Bol. Acad. peru. leng. 65. 2019 (101-127)

\title{
ESTRATEGIAS NARRATIVAS DE RUPTURA EN CRÓNICA DE MÚSICOS Y DIABLOS: ENTRE LA CRÓNICA HISTORIOGRÁFICA Y LA SÁTIRA MENIPEA
}

\section{NARRATIVE STRATEGIES IN CRÓNICA DE MÚSICOS Y DIABLOS: BETWEEN THE HISTORIOGRAPHICAL CHRONICLE AND THE MENIPPEAN SATIRE}

\author{
Fernando Montalvo Yamunaqué \\ Universidad Peruana de Ciencias Aplicadas \\ Universidad Nacional Mayor de San Marcos
}

Resumen:

El objetivo del presente trabajo de investigación es realizar una primera aproximación al estudio de las estrategias narrativas presentes en Crónica de músicos y diablos (1991), una de las novelas más destacadas de Gregorio Martínez. Es reconocido el interés de este autor por recuperar la experiencia vital y social de los estratos populares de la sociedad peruana, asunto en el que ha demostrado gran sensibilidad, una sensualidad desbordante y un poderoso humor. Postulamos que, en Crónica de músicos $y$ diablos, también podemos observar la inclinación del novelista por construir un discurso crítico en torno a la crónica historiográfica, la cual tradicionalmente ha sido valorada por su capacidad de representación de la historia fundacional peruana. Creemos que la novela de Martínez construye una serie de estrategias narrativas en estrecho diálogo con este 
género discursivo, con el objeto de cuestionar hondamente su capacidad mimética, en tanto la representación efectiva de la realidad social que ofrece es cuestionada por su tendencia a sustentarse sobre la visión de los sujetos de poder. Para este trabajo, partimos del marco teórico diseñado por Mijaíl Bajtín en torno al carnaval literario y la sátira menipa, conceptos que también se encuentran contextualizados para la realidad literaria latinoamericana por José Vilahomat. Estos lineamientos nos serán de utilidad en tanto sugieren pautas para la lectura de novelas que se postulan como anticanónicas a partir del análisis de su estructura.

\section{Abstract:}

The purpose of this research paper is to provide a first look at the study of the narrative strategies which are present at Crónica de músicos y diablos (1991), one of Gregorio Martinez's most remarkable novels. It is well known the interest of this author to regain the vital and social experience from popular classes of the Peruvian society, matter in which he has shown great sensitivity, an exuberant sensuality and a powerful sense of humor. We believe that, in Crónica de músicos y diablos, it can also be appreciated the novelist's inclination to create a critical speech about the historiographical chronicle which it has traditionally been valued due to its capability to represent Peruvian foundation's history. We think that Martinez's novel builds a series of narrative strategies which are linked to this discursive genre in order to deeply question its mimetic capacity. Moreover the effective representation of the social reality that he offers it's questioned because of its tendency to sustain itself on the vision of power's subjects. For this paper we start from the theorical model designed by Mikhail Bakhtin which talks about the literary carnival and the menippean satire, concepts that are also contextualized for the Latin American literary reality by José Vilahomat. These guidelines will be useful due to the fact that they suggest tips for interpreting non-canonical novels by analizing their structures.

Palabras clave: carnaval literario, sátira menipea, literatura afroperuana, crónicas del Nuevo Mundo.

Key words: literary carnival, menippean satire, Afro-Peruvian literature, chronicles of the New World. 
Fecha de recepción: 29/03/2019

Fecha de aceptación: $\quad 31 / 05 / 2019$

\section{Introducción}

Cualquier parecido o semejanza entre lo que aparece trascripto aquí y lo correspondiente al renglón de los hechos y de las personas de carne y hueso [,] es pura y casual coincidencia [,] algo similar a la historia de esa canción que dice que en el bosque de la China una chica se perdió (Martínez, 1991: sin página).

Con estas versadas líneas a modo de prólogo, da inicio Crónica de músicos y diablos, segunda novela de Gregorio Martínez. Percibimos en ellas una suerte de advertencia acerca de la falta de autenticidad de los hechos que se expondrán en el relato, aunque en un tono jocoso e irónico que tiene un impacto totalmente contrario: sugerir el sustrato real de lo que se va a narrar. La inducción hacia una lectura activa, basada en la contraposición tanto de hechos ficticios como reales, es una de las características de la estructura narrativa de la novela, además de funcionar como herramienta de uno de sus fines: la revisión crítica de la historia (Reverte 2018: 232-233). Solo recordemos que en el «Prólogo» de la novela, además de las líneas citadas al inicio del presente artículo, el autor compone una especie de collage textual compuesto por documentos reales. Destacan los avisos publicados en el Mercurio Peruano, así como ordenanzas y minutas de compra-venta de esclavos fechados en la época colonial. Un procedimiento semejante se realiza en el «Epílogo», en donde el autor selecciona un conjunto de testimonios y artículos periodísticos sobre la masacre de Parcona. Estos elementos, además de las referencias históricas introducidas en la narración, generan la contraposición ficciónno ficción a la que hacemos referencia.

Para elaborar su texto, el autor emplea como material de trabajo el discurso historiográfico colonial y republicano, aunque desde una 
indudable perspectiva literaria (Carrillo 2010: 127), lo que por supuesto no invalida su propuesta revisionista. Señala Forgues, por ejemplo, que «con el epílogo constituido por documentos y testimonios históricos [...] la ficción, sin perder su carácter de ficción, toma nuevas fuerzas al unirse con la realidad histórica, materia del prólogo» (2009: 122). Ismael Márquez ha indicado, a su vez, que existe cierta simetría entre la novela de Martínez y la crónica de Guamán Poma, en la cual fundamenta «su cuestionamiento de la historiografía peruana y del género mismo que utiliza» (1994: 58). Añade el crítico que, entre Crónica de músicos y diablos y la Nueva corónica y buen gobierno (1615), se establecen vínculos de semejanza en la adopción de las formas oficiales de la relación colonial y la intención de reconstrucción de la historia de los pueblos vencidos tras la conquista.

La reelaboración ficcional y estética de la historia le brinda al autor la libertad de introducir diversas variantes a hechos registrados por la historia hegemónica con el objeto de crear un contexto crítico y cuestionador. Alejandra Huespe ha señalado, en esa línea, que en la novela «entran en conflicto diferentes versiones ficcionalizadas de sucesos históricos que se oponen al 'olvido obligatorio' impuesto desde el discurso historiográfico» (2012: 137), por lo que el relato apela a una recuperación de la memoria popular que evidencie los vacíos e injusticias del discurso oficial. El ya citado Ismael Márquez ha indicado también que Crónica de músicos y diablos funciona como una especie de «caballo de Troya para subvertir un orden de cosas desde dentro, tanto literaria como ideológicamente» (1994: 58). Por su parte, Milagros Carazas asevera que el fin este relato novelístico es "proponer una relectura cuestionadora y paródica del pasado histórico (la época colonial y la República) y construir una innovadora imagen del sujeto afroperuano [...]» (2011: 131).

En ese contexto de investigación, nos proponemos aportar a esta discusión a partir de un análisis de las estrategias narrativas planteadas por la novela en consonancia con las formas de la crónica histórica. Consideramos que la evaluación y cuestionamiento del discurso historiográfico pasa no solo por un trabajo del autor en el plano del contenido, sino también en los vericuetos de la estructura narrativa. Como afirma Roland Barthes, en el orden del discurso, «el sentido no 
https://doi.org/10.46744/bapl.201901.006

está "al final del relato", sino que lo atraviesa», por lo que «todo tiene un sentido o nada lo tiene» (1972: 15-17).

\section{Las formas de la sátira menipea}

Consideramos que es posible establecer interesantes lazos entre Crónica de músicos y diablos y la sátira menipea, un género que se define por ser manifestación literaria del carnaval bajtiniano. Describir estas relaciones, en nuestra opinión, nos permite referirnos al texto de Martínez no solo como novela de ruptura ideológica y de tendencia estéticamente crítica, sino también como un relato estructurado, de manera que se constituye como texto anti-discursivo en relación a la crónica histórica.

En Problemas de la poética de Dostoievski ([1979] 2003), Bajtín propone que uno de los primeros ejemplos de literatura bajo las coordenadas de la carnavalización lo constituye el género cómicoserio, del cual se desprende el diálogo socrático, así como otras manifestaciones caracterizadas por el empleo de un discurso subversivo de formas y lenguaje extravagantes. Estos «géneros menores» fueron usualmente el soporte formal para el sustento de una noción socrática de la verdad, a saber, una verdad de naturaleza dialógica y conflictiva, opuesta a verdades absolutas y monologismos obtusos. Uno de estos géneros lo constituye la sátira menipea, la cual, en términos generales, se define como una modalidad de gran plasticidad formal dotada de una considerable libertad para abordar cuestiones temáticas. Bajtín le atribuye hasta 14 características, de las cuales nos interesa señalar solo las tres más relevantes. La primera alude al despliegue de una gran capacidad inventiva del género que le permite al autor superar los límites historiográficos y formales de la épica clásica, así como reinventar y trascender el método dialógico socrático. Bajtín sostiene que se encuentra «libre de la tradición y no se ajusta a ninguna exigencia de verosimilitud externa», por lo que «se destaca por una excepcional libertad de invención temática y filosófica» (2003: 167). Ello, por supuesto, no implica un distanciamiento de la tradición literaria, sino un reposicionamiento del punto de vista del texto como artefacto de 
sentido que le permite al autor desmontar sus propios principios y resignificar sus funciones.

La segunda característica que deseamos resaltar es su relación con la verdad. La sátira menipea hace uso de una fantasía sin freno, la cual no constituye un simple artificio extravagante. En realidad, responde a estrategias para abordar intelectivamente la realidad. Se constituye, en ese sentido, como un método para crear situaciones inusuales y de gran excepcionalidad que pongan a prueba una idea filosófica $o$ una verdad considerada absoluta. En palabras de Bajtín: «lo fantástico sirve no para encarnar positivamente la verdad, sino para buscarla y provocarla y, sobre todo, ponerla a prueba» (2003: 167). Insistamos en que el carácter de esta verdad no es privada ni individual: la sátira menipea no cuestiona a individuos particulares o un carácter humano específico, sino a una verdad que dé sentido a la realidad. Es por ello que suele definírsele como aquel discurso literario que se sustenta en la confrontación de las «ultimas cuestiones del mundo» (2003: 169).

La tercera característica refiere a su empleo diverso e intercalado de géneros desde una posición distante y paródica del autor, lo que promueve el enriquecimiento del discurso gracias a los tonos y estilos a los que recurre. Sobre todo, sostiene una nueva actitud del autor frente al rol de la palabra como agente significante del mundo que nos rodea. El cuestionamiento del rol del lenguaje como referente de la verdad es un asunto medular en la menipea.

Tal como afirma el autor ruso, en periodos modernos el influjo de la menipea también se ha dejado sentir, lo que se evidencia en el aprovechamiento que ciertas corrientes literarias han hecho de sus recursos a partir de una adaptación creativa y renovadora de estos. Es más, Bajtín afirma que «la menipea en las literaturas contemporáneas ha sido el transmisor por excelencia de las formas más concentradas y ostensibles de la carnavalización» (2003: 200). En consecuencia, el autor entiende como género de la menipea no a un canon establecido para estudiar la Antigüedad clásica, sino a un conjunto de características 
discursivas que constituyen la esencia básica de esta práctica literaria. De este modo, es posible entender que, en tiempos actuales, podamos encontrar literatura con una fuerte tendencia a replicar los parámetros de este género. Acaso ello se deba a su carácter de actualidad, lo que impele al pensador a afirmar que se trata de un género cercano al periodismo moderno, en tanto tiene predilección por abordar dialógicamente las tendencias ideológicas de su tiempo.

Si pensamos al respecto en una realidad más cercana a la nuestra, valga decir la cultura latinoamericana actual, es posible encontrar puntos en coincidencia entre las manifestaciones literarias de nuestra región y esta tendencia satírico-carnavalesca. Existen trabajos de investigación que se han encargado de rastrear estas nuevas formas de la novela, la cual se sustenta en la parodia de los llamados "géneros menores» modernos desde una actitud mental satírico-menipea. Se ha afirmado, por ejemplo, que esta tendencia puede rastrearse desde la década de los setenta y que una conceptualización moderna de la menipea posibilita asignar características adecuadas a la estética literaria de las últimas décadas, en cuanto continuación de los estudios críticos posteriores al Boom (Vilahomat, 2010b: 1). Obras significativas que ilustran esta tendencia las constituyen Cocuyo (1990), de Severo Sarduy; Los detectives salvajes (1998), de Roberto Bolaño; El rey de la Habana (2001) de Pedro Juan Gutiérrez; Sin tentas no hay paraíso (2005), de Gustavo Bolívar; entre otras.

Con el aporte crítico de las propuestas de Mijaíl Bajtín y Northrop Frye, José Vilahomat sostiene que las novelas latinoamericanas, desde la década de los setenta, manifiestan en su estructura formas de la sátira menipea que las convierten en «instrumentos de análisis sobre los procesos de lenguaje y las narrativas construidas» (2010a: párr. 1). Es decir, se erige como una herramienta discursiva que permite desmontar la realidad y posicionar al autor como un observador externo a la ideología dominante. En ese sentido, se trata de un carácter de la menipea latinoamericana esencialmente antidiscursiva que cuestiona, incluso, la misma capacidad del lenguaje para representar a la realidad, para lo cual se basa en el uso paródico de procesos miméticos desgastados 
y caducos (2010b: 2). Podemos afirmar, entonces, que este género refleja la decadencia y la crisis de la representación de una realidad en cuestionamiento, por lo que no sorprende que surja en periodos de cambios e inflexión históricos. En síntesis, en palabras de Vilahomat, la sátira menipea «como actitud mental es una especie de supra-género que conecta la obra literaria con un periodo estético y con todo el tejido semiótico que la precede y la trasciende» (2010a: párr. 15).

\section{Estructuras narrativas de ruptura en Crónica de músicos y diablos}

Se han identificado tres tipos de sátira en la literatura latinoamericana que se desprenden del mencionado género. En primer lugar, destaca la sátira menipea distópica, definida por su parodia de géneros como la ciencia ficción, y las novelas de viajes y aventuras, así como por la construcción de una topografía apocalíptica en la que los grandes centros urbanos han colapsado «sobrecogido[s] por la sobrepoblación y la destrucción de los ecosistemas» (párr. 37). En segundo lugar, tenemos a la sátira menipea histriónica, la cual «parodia la estructura de la picaresca, reformando el personaje del pícaro y usando temas actuales» (párr. 41). Estos personajes buscan supervivir en un medio social agreste con el que deben de negociar su representación desde una postura contraria al discurso oficial. El tercer tipo de sátira es la que nos interesa abordar: la sátira menipea épica. Sus características responden a los motivos novelísticos de Crónica de músicos y diablos. Antes de discutir los mecanismos precisos que estructuran esta novela en consonancia con el género descrito, creemos conveniente justificar la pertinencia del análisis de nuestro texto bajo el marco teórico reseñado.

En líneas generales, podemos decir que la sátira menipea épica destaca por su interés por narrar hechos relevantes de la historia, interés que responde a una narración de tono revisionista que adquiere importancia en el marco de una crisis social. Este rasgo, en la novela en cuestión, se evidencia en una «vuelta al pasado» que busca discutir hechos que son fundamentales para comprender los procesos sociales del país. La narración de Martínez, en ese sentido, se ancla en la necesidad de revisar 
https://doi.org/10.46744/bapl.201901.006

la historia a fin de desmitificar el discurso oficial, el cual se ha anquilosado en estereotipos, costumbres y una historiografía que resultan insuficientes para representar una realidad nueva que emerge desde la otredad y desde lo marginal (Carazas 2004; Forgues 2009; Carrillo 2010). De allí la crisis en la capacidad de representación de la realidad por parte del discurso oficial —el cual nosotros limitamos, para fines del trabajo, a la capacidad mimética de discurso cronístico- y la función de una literatura de carácter subversivo que pretende llenar este vacío desde la ficción.

En segundo lugar, el discurso de la sátira menipea épica está teñido por un tono escéptico que se manifiesta a partir del uso de la parodia y de una fantasía liberada. Usualmente, el recurso de la fantasía se manifiesta en este género a través de la construcción de un escenario estrambótico que rompe con la realidad convencional. Frye sostiene que esta fantasía se caracteriza por ser grotesca y absurda (2000: 224). Vilahomat añade que la creación de topologías imaginarias, el empleo de las fábulas y la asociación de estos recursos a la complejidad del texto cumplen suficientemente con este elemento requerido por la sátira (2010a: párr. 63). En ese orden de cosas, consideramos que en Crónica de músicos y diablos el narrador recurre a su empleo a partir de la creación de eventos que, para la historiografía oficial, no han sido registrados en el devenir histórico legitimado por este régimen. Ello le permite introducir en la historia hegemónica un conjunto de improntas, ocurrencias y eventos artificiales que tienen el efecto de cuestionarla y generar nuevos sentidos. Este choque entre un registro histórico y otro ficcional - cuya esencia dialógica resulta evidente para el lector- genera astutamente un conflicto cognitivo que tiene por fin poner a prueba el discurso oficial.

Por otro lado, la mentalidad satírica menipea implica, además de «la narración de hechos históricos», rasgos que la vinculan con una narración escéptica "que se limita a mostrarnos nuestras propias contradicciones sin mostrar posición» o crítica directa (Vilahomat 2010a: párr. 27). A pesar de que la narración apela a un humor desbordante que trasforma el mundo en una realidad carnavalizada, no es posible dejar de percibir cierto tono escéptico del narrador y los personajes frente a una realidad áspera y poco abierta al cambio y la integración del sujeto marginal. 
Como podemos observar, es posible analizar esta preciosa novela de Gregorio Martínez dentro de las coordenadas de la sátira menipea moderna en su vertiente épica. Con el objeto de profundizar en esta discusión, propondremos realizar un análisis de uno de los aspectos medulares que estructuran la novela, a saber, el cuestionamiento de la capacidad mimética del discurso oficial, representado este por la crónica histórica. Los lineamientos definidos por el género de la sátira menipea para la novelística latinoamericana nos permiten acercarnos al texto bajo los parámetros conceptuales ya descritos.

\subsection{Cuestionamiento de la capacidad mimética del discurso oficial}

Como ya se ha señalado, en Crónica de músicos y diablos la crítica especializada ha identificado claramente que la novela busca cuestionar la representación social e histórica producida desde el discurso oficial. Carrillo Jara, por ejemplo, ha planteado acertadamente que el relato constituye un discurso histórico alternativo al de la historia hegemónica. Señala, sin embargo, que el texto no pretende estructurarse como una crónica, puesto que indudablemente nos encontramos frente a una novela (2010: 127-129). Esta es una afirmación pertinente que no niega, por supuesto, que se pueda establecer relaciones entre ambos discursos. Consideramos que hay diversas evidencias que revelan que la novela toma como referencia a la crónica a fin de estructurar su propio relato. Podemos mencionar algunos de estos indicios:

a. El vistoso título de la novela nos sugiere la posibilidad de adentrarnos a un intenso registro histórico de carácter popular y con un fuerte sabor a fiesta patronal.

b. El empleo de un léxico y una dicción arcaizante nos recuerdan los usos lingüísticos propios de la crónica de los primeros siglos coloniales.

c. La referencia a diversos sucesos fundacionales de la nación peruana, tales como la violenta colonización y el esclavismo de la comunidad negra.

d. El registro de un relato en el que los mecanismos históricos adquieren mayor relieve que los personajes en sí mismos. 
https://doi.org/10.46744/bapl.201901.006

En ese orden de cosas, el último capítulo, intitulado «Sondondo, donde Felipe Guamán Puma escribió el comienzo de esta relación», refuerza la idea de que, efectivamente, Crónica de músicos y diablos funda el relato a partir de las coordenadas estipuladas por el género cronístico. Se establece una especie de continuidad de la Nueva corónica y buen gobierno (1615) sobre la base de la recuperación de la memoria popular y la construcción de una historia desde la visión de los vencidos (Márquez 1994: 58).

No pretendemos afirmar que nos encontramos frente a una réplica imitativa del género. Estos rasgos responden, más bien, a un texto en el que la pretensión de revisar el pasado histórico se articula dialógicamente con el fin de evaluar las formas narrativas en las que se sustenta. En el presente apartado sostendremos que el contacto entre estos dos tipos de discursos tiene como fin evidenciar las limitaciones miméticas de la crónica histórica e instaurar un discurso que, desde la ficción, genere alternativas narrativas de mayores alcances que la crónica en el plano de la representación. Esto puede evidenciarse si observamos detenidamente las estrategias narrativas propuesta por el autor. Describimos este mecanismo a partir de dos subtemas que nos permiten organizar mejor nuestra exposición: por un lado, la voz narrativa en la novela y, por el otro, las analogías paródicas.

\subsubsection{Las implicancias de la voz narrativa}

Para poder iniciar esta discusión, consideremos el estatuto discursivo de la crónica, referente recurrente en la obra de Martínez. Como bien sabemos, este género narrativo, desde el punto de vista de la mímesis, se define como una herramienta que pretende representar la realidad a partir de una práctica que se encuentra legitimada gracias a su cualidad de «fuente histórica». Por supuesto, este punto genera diversas controversias, debido a la no necesaria correspondencia entre discurso y realidad, asunto que finalmente no es indispensable para que se cumplan tales funciones de representación. Solo recordemos, junto a Auerbach en su célebre libro Mímesis, que la Biblia, la cual nos ofrece una especie de crónica del pasado mítico, se erige como un discurso que, sin corresponder a 
una realidad verdadera, aspira a ofrecer su perfecta representación, así como una verdad absoluta de mundo: «El mundo de los relatos bíblicos no se contenta con ser una realidad histórica, sino que pretende ser el único mundo verdadero, destinado al dominio exclusivo» (1996: 20). Esto ha generado, para los estudios actuales, la controversia según la cual realidad y ficción suponen un estado de confusión no resuelta en el género (Alburquerque 2008: 13).

Es este el estatuto de la denominada crónica de Indias, escrita en América durante el siglo Xvi. Nancy Salas agrega que este tipo narrativo implicó también «una forma empírica de conocimiento acerca de una realidad distinta, un modelo para explicar la realidad mediante el registro de los hechos de forma narrativa» (Salas 2009: 103). Efectivamente, los cronistas que exploraron el Nuevo Mundo, frente a una situación novedosa que ponía en juego su propia identidad cultural y religiosa, expusieron su testimonio personal como una forma de comprender este nuevo entorno geográfico y demográfico de acuerdo con sus parámetros mentales. La crónica supuso, asimismo, la construcción de un discurso que en la práctica era monologante, dado que irrumpió en un medio ágrafo en el que primaba la oralidad. En ese sentido, no tuvieron un discurso opositor desde la escritura que contrastara con su versión de los hechos: la voz dominante se originaba siempre desde el poder hegemónico del conquistador europeo. La situación antes descrita le brindaba a la crónica un valor arbitrario: el de su estatuto de genuina verdad, el cual estaba sustentado, como se ha dicho, en la experiencia y la vivencia personal del escritor. Como bien afirma Salas:

El contexto discursivo de las Crónicas de Indias en gran parte se forma en América y se inscribe en ese fenómeno más que se llama Narrativa Testimonial, cuyo fundamento está en el pacto de lectura por el cual se establece que se contará la verdad de los hechos narrados, a la vez que se constituye en prueba de esa verdad que el autor se declare actor o testigo (mediato o inmediato) de esos hechos (2009: 103).

Es usual, pues, que las crónicas se encuentren escritas en primera persona para otorgarle legitimidad al relato y cumplir con el pacto 
https://doi.org/10.46744/bapl.201901.006

testimonial y de referencia a la verdad instaurada por el discurso. Se ha afirmado ya que los escritores de crónicas «narran en primera persona las vicisitudes de sus viajes y hacen explícita en los prólogos la veracidad de lo que cuentan, como algo realmente vivido por ellos y no inventado» (Alburquerque 2008: 13). Ello explica, en parte, que los cronistas no manifestaran duda alguna de la autenticidad de los hechos que refieren. Por citar un ejemplo, Cieza de León afirma, en una de sus célebres crónicas, que «[...] vínome gran deseo de escribir algunas de ellas [eventos notables ocurridos en el Nuevo Mundo], de lo que yo por mis propios ojos había visto y también había oído a personas de gran crédito». Más adelante culmina diciendo que su historia «va llena de verdades» (1988: 17-22).

Dicho esto, es pertinente preguntarnos de qué modo el género es reelaborado por Martínez en su reconocida novela. Debemos considerar que el escritor de Coyungo retoma ciertos principios de la crónica practicada por el Grupo Narración para construir un discurso de protesta y referir una realidad social desde la perspectiva del sujeto marginal, pero con claros fines estéticos y desde la ficción. Creemos que, en este proceso, la crítica y la autorreflexión no posan su juicio solo hacia la historia, sino también hacia el discurso en la que se sustenta. La crónica, en ese sentido, se convierte en materia de autorreflexión sobre su propio estatuto discursivo, así como herramienta de análisis de la realidad. Revisemos las primeras líneas de Crónica de músicos y diablos, dado que resultan fundamentales para sentar la posición del narrador frente a esta controversia. En ellas, como afirma Forgues, «tenemos sintetizadas al mismo tiempo la historia de la Conquista que nos ha llegado a través de los cronistas y su cuestionamiento» (Forgues, 2009: 118). El pasaje es como sigue:

Muchos años atrás, en el oscurecido tiempo de las antiguas leyes, cuando se hacían torres de vidrio y los conquistadores oficiaban esmeradamente como los empinados señorones de la existencia terrenal; en la época de los frailes y de conventos, en la que florecían sin mengua los templos de calicanto, erigidos a punta del sudor gratuito de los indios de servidumbre y de la pujazón obligatoria de los negros esclavos; en tales tiempos de 
inflamados incordios fue que apareció en Cahuachi, arrastrado por lo ventarrones del desierto, alguien premunido de cuerpo y de alma que decía y aseguraba, con juramentos de diversa índole, que se llamaba Pedro de Guzmán, por la gracia divina de Dios nuestro señor, y que le sobraban de yapa otros nombres de cumplimiento para que lo supieran mientras (Martínez, 1991: 21).

Quisiéramos señalar algunos aspectos que se desprenden del pasaje citado líneas arriba, los cuales permiten describir la posición discursiva del narrador. En primer lugar, este se distancia del uso de la primera persona, recurso propio de la crónica histórica, lo que implica que el estatuto de verdad ya no se sustenta en el testimonio del sujeto enunciador ni en su experiencia. En efecto, la primera persona gramatical configura una acción verbal de alcances significativamente restringidos, pues reduce el punto de vista que da sentido al total del mundo representado a la sola mirada de quien emite el relato. La primera persona, en la crónica, se cierne siempre desde un yo que limita la posibilidad de la voz del otro o, como sugiere Salas, nos ofrecerá una versión «según su condición y desde sus vivencias, sobre las que reflexiona en el acto de contar, discriminando aquellas que salen fuera de su racionalidad» (2009: 104).

En ese orden de cosas, es notable observar que todo el discurso narrativo de Crónica de músicos y diablos se sustenta en la instauración de un narrador extradiegétic/heterodiegético, el cual refiere, según Genette, a aquel que no emite su narración desde el interior de la historia narrada. Tampoco se encuentra vinculado a ella, dado que refiere la historia de otro y no la suya propia (1989: 270286). Ello sugiere un registro totalizador capaz de representar un devenir histórico amplio que puede abarcar siglos. El proceso de la enunciación, en ese contexto, surge en un tiempo indeterminado o, como sostiene Genette para este tipo de narrador, desde «un momento único y sin progresión» (279). Estas implicancias narrativas remiten a una de las características de la novela: el distanciamiento de la voz enunciativa de aquellos hechos históricos que se desean describir. Es decir, aunque es posible leer una crítica social en la narración, esta no 
https://doi.org/10.46744/bapl.201901.006

adquiere los rasgos de un cuestionamiento proveniente de una voz individualizada o personal —ello ocurría en las crónicas de la revista Narración-, sino los de un discurso impersonal que se disuelve en el espectro estético de la novela.

El narrador extradiegético/heterodiegético, debido a su carácter de conocedor omnisciente de los eventos narrativos del discurso, está relacionado con lo que Vilahomat define, para la sátira menipea épica latinoamericana, como «la configuración de una visión totalizadora». Esta postura narrativa permite recorridos amplios del discurso a través de espacio y el tiempo de los eventos experimentados por los personajes, lo que «sirve para dar el sentido de catascopia (o visión desde arriba) propio de la SM» (2010a: párr. 22). Podemos notar, precisamente, este movimiento en el pasaje citado, dado que la narración da inicio con una pincelada que retrata en pocas líneas la época histórica que inicia lo que será la nación peruana: una época de luchas fratricidas durante las guerras civiles que denomina "tiempos inflamados de incordios», así como el costo humano que significó construir esa sociedad colonial sobre la base de la "pujazón obligatoria de los negros esclavos». Ello nos ofrece un panorama que, desde las primeras líneas, se constituye como un espacio social conflictivo y opresor.

Esta visión totalizadora se amplía, a lo largo del resto de la narración, hacia la historia colonial, particularmente la historia negra y sus rebeliones, así como las penurias de una república que terminó siendo ilusoria. En «Esclavos y cimarrones V», el narrador expone que, en pleno hervor republicano, tras el apoyo que significó la participación de huestes negras en las luchas de independencia, la servidumbre y la esclavitud seguían siendo, en el Perú, prácticas de «beneficio exclusivo de los criollos ricos que tanto se habían llenado la boca de palabras, hablando y pregonando la revolución de la corona española» (1991: 147). Un siglo después, hacia la década del veinte de siglo pasado, en su recorrido en mula hacia Sondondo, afirma sobre la familia Guzmán que «ni en los tiempo de Concolorcorvo, el divino postillón que recorría a lomo de mula la América entera; ni ese entonces se había visto bajar por 
el cause seco y pedregoso del río de Nasca un regimiento de acémilas tan exagerado» (1991: 243), con lo que completa una representación que no solo tiene interés en asumir un recorrido temporal, en tanto se establece un parangón entre un personaje colonial y otros republicanos, sino también geográfico.

Recordemos que Alonso Carrió de Valdera, conocido como Concolorcorvo, autor del Lazarillo de ciegos y caminantes, fue un escritor y cronista español que vivió parte importante de su vida en el virreinato del Perú. En su más celebre obra, aporta un registro importante de la geografía, cultura de gran parte del territorio que le pertenecía al virreinato a partir de un relato de viajes. En Crónica de músicos y diablos, algunos capítulos de la novela responden también a esa necesidad de representación del entorno en su relación con la cosmovisión de los personajes y desde una visión sobre la geografía, significativamente distinta a la del uso utilitario que le darían los conquistadores. Los capítulos de «Arena natura» y «Mar oceána», abocados a descubrir el espacio costeño durante el recorrido de la familia hacia la capital, dan cuenta de ello. El contraste que genera ello con lo narrado en el primer capítulo, en donde se da cuenta del arribo de Pedro de Guzmán al Perú y su pretensión de llegar, es evidente. Según los documentos que ostentaba Pedro de Guzmán, pretendía llegar a un «lugar ignoto, en una tierra casi incógnita, en apariencia sin derrotero conocido, denominada Huanuhuanu» (21), en donde explotaría el oro. La referencia paródica que hace el narrador recae en una descripción del espacio que solo adquiere sentido en cuanto puede ser explotado.

La novela, en ese sentido, se estructura a partir de una transición espacio-temporal que repasa etapas importantes de la historia del país. Se trata de una mirada amplia que busca poner en contacto todo el proceso histórico desde una visión total, ello con el objeto de traslucir un punto de vista crítico. La narración, en lugar de seguir un orden estrictamente cronológico como lo sugiere el género cronístico, procede a intercalar eventos ubicados en tiempos y espacios geográficos diversos, de modo que el sentido de totalidad se logra gracias a la simultaneidad con la que somos testigos de, por ejemplo, un levantamiento colonial en el palenque de Huachipa para, pocas páginas 
https://doi.org/10.46744/bapl.201901.006

después, ser espectadores de los sangrientos sucesos de Parcona en el siglo xx. Los desplazamientos espacio-temporales rompen de ese modo con la linealidad de la crónica histórica para configurar un relato cuyo sentido depende de esta correlación de carácter hondamente dialógico. En ese sentido, al conectar los contextos sociales del esclavo cimarrón Antonio Lucumí o de Manuela Escate, una de las líderes de Parcona, se observa una realidad social en la que se ha sistematizado el abuso, la discriminación y donde la marginación de ciertos componentes de la sociedad se ha normalizado.

\subsubsection{Analogías paródicas: entre lo cómico y lo serio}

La configuración de un narrador extradiegético/heterodiegético en Crónica de músicos y diablos también permite que el discurso narrativo redefina la pretensión del estatuto de verdad propio de la crónica. Esta es, por supuesto, una forma de cuestionar su capacidad mimética a partir de la estructura narrativa del relato. Al no asumir una voz en primera persona que exponga una verdad basada en la experiencia individual o en el testimonio, la voz del relato se sumerge en un uso gramatical que la libera de caer en la representación de una realidad social desde un punto de vista parcial, ligado siempre a las vivencias de uno o varios personajes. Recordemos que la crítica en la sátira menipea nunca es personalizada, sino que apunta a cuestionar una verdad que sustenta las «ultimas cuestiones del mundo» (Bajtín, 2003: 169).

No queremos decir con ello, por supuesto, que la novela no asume una postura ideológica, lo que técnicamente no es posible. Claramente existe una crítica al discurso oficial de la historia peruana, pero esta no se ejecuta a partir de un cuestionamiento directo ni de la crítica encarnizada - propia del panfleto o de la crónica producida en el seno de la revista Narración - , sino que se sublima en los recursos narrativos y estéticos que despliega el relato. En algunos casos, esta visión de la realidad discurre a partir de las acciones de los mismos personajes, sin que medie ninguna alusión ideológica directa. En otras ocasiones, se procede a evidenciar esta postura a partir de las estrategias de narrador omnisciente, de las cuales sobresale el empleo de la parodia y la ironía y el humor. José Vilahomat 
ya ha descrito esta característica de la sátira menipea en algunas novelas latinoamericanas en los siguientes términos: «[...] la expresión satírica se da libremente, sin caer en una crítica directa o en una tesis que busca esencias». Más adelante afirma que «sin necesidad de hacer juicios ideológicos, el narrador describe elementos específicos de una realidad que constata» (2010a: párr. 25-26).

Quisiéramos centrarnos en un punto en especial: la parodia como herramienta de crítica social que sublima la postura ideológica del narrador desde una postura novelística y estética. Esta no se construye como una parodia personal ni se dirige hacia un personaje determinado. Tampoco busca cuestionar un tipo social específico. El tipo de parodia de la sátira menipea en Latinoamérica tiene como objeto el cuestionamiento de mecanismos sociales, por lo que, por extensión, podemos asociarla a todo un proceso histórico cuya representación es interpretada como en estado de crisis. Tal como afirma Bajtín, se trata de "poner a prueba la verdad, la idea, y no un carácter humano individual o socialmente determinado» (2003: 168). Esto se manifiesta, en Crónica de músicos y diablos, a partir de procesos en la narración que denominamos analogías paródicas. De acuerdo con nuestra lectura, la novela configura un conjunto de escenas en las que se establece un doble discurso basado en la articulación de dos realidades contrapuestas que son comparadas: en primer lugar, el discurso oficial, serio, hegemónico, el cual es sugerido por las claves del género de la crónica a los que recurre la novela. Y, en segundo lugar, la realidad representada, vista como distópica, representada a partir de la parodia, el humor y la ironía.

La apelación al género de la crónica sirve como referente para declarar la situacionalidad historiográfica del relato, además de generar una reminiscencia de su rol como discurso con capacidad de representación mimética. De ahí su seriedad y el posterior contraste cuestionador al que es sometido por medio de procesos paródicos. Nos explicamos: esta representación discursiva es claramente cuestionada por el doble sentido que proviene del empleo de una parodia que desvela las fisuras del discurso oficial. El contraste producido por este mecanismo genera que la crónica sea postulada 
https://doi.org/10.46744/bapl.201901.006

desde una mirada desautomatizada, lo que causa su desautorización como posibilidad mimética.

Veamos algunos pasajes que nos permiten ilustrar estas ideas. En primer lugar, podemos citar la descripción del arribo de Pedro de Guzmán al virreinato del Perú. El narrador revela que este personaje «decía y aseguraba, con juramentos de diversa índole, que se llamaba Pedro de Guzmán, por la gracia divina de Dios nuestro Señor, y que le sobraban de yapa otros nombres de cumplimiento para que lo supieran mientras» (Martínez, 1991: 21). Esta necesidad por aclarar su origen tiene por fin despejar cualquier duda de que «era un hijodalgo español tangible y de legítima estirpe, y si quedaban dudas estaba dispuesto, de buen talante, para que cualquier entendido en genealogía le sopesara los compañones con ambas manos» (1991: 21). Como se observa, en estas breves líneas se han abroquelado dos niveles del discurso que producen un conflicto dialógico a través del cual se crean sentidos nuevos. Por un lado, el primer nivel apela a las formas tradicionales de la crónica de Indias, a partir del empleo de un español arcaizante, así como a usos propios del género y de la época. Por ejemplo, en la invocación a una instancia divina o al orden regio a fin de satisfacer la necesidad de comprobar el origen noble de Pedro de Guzmán, se observa el seguimiento de pautas necesarias que le permitían al individuo actuar legítimamente dentro del orden oficial establecido.

Esta pretensión de legitimación social la podemos observar, efectivamente, en la famosa portada de los Comentarios reales de los incas, en la que el célebre Inca Garcilaso de la Vega se presenta como «natural del Cusco y Capitán de su Magestad», con lo que resalta su legítimo estatus social como servidor del rey. Por otro lado, esta crónica, dedicada a la princesa Doña Catalina de Portugal, apela numerosas veces a la divinidad. Un caso representativo lo constituye el escudo del escritor, en el que se consigna una invocación a la Virgen María en los siguientes términos: «Ave María / Gratia Plena» (Garcilaso, 1991).

Hasta este punto, el relato se comporta dentro de los márgenes «serios» de la crónica; sin embargo, se percibe simultáneamente una 
carnavalización del discurso cronístico producto de la irrupción de la parodia y el humor. Este constituye el segundo nivel discursivo. Efectivamente, entre las líneas citadas, se narra también que a Pedro de Guzmán «le sobran de yapa otros nombres» y además estaba dispuesto a que «cualquier entendido en genealogía le sopesara los compañones», lo que en buen castellano quiere decir que invitaba a los dudosos de su origen noble a cogerle sus partes pudendas.

Esta interacción entre lo cómico y lo serio ciertamente pone en cuestionamiento el discurso hegemónico, a partir de la construcción de un personaje ficcional que rompe todo parámetro establecido por el género de la crónica. El origen dudoso de Pedro de Guzmán, asunto que podría adquirir importancia en el contexto de la crónica historiográfica, nos brinda una idea de cómo se ha constituido el fundamento del relato novelístico, pues la novela funda su estatuto discursivo en el cuestionamiento y no en la veracidad mimética propia de la crónica, lo que la dota de un carácter dialógico y crítico. En Crónica de músicos y diablos nos encontramos frente a un discurso que, enunciado desde un narrador extradiegético/heterodiegético, no tiene interés en exponer certezas, sino hechos cuya veracidad se encuentra constantemente discutidas. Podemos afirmar entonces que el tono humorístico y la parodia del género implican la cancelación del registro serio al que apela la crónica, así como su estatuto de verdad legítima. Se instala de esta manera un nuevo discurso de rasgos iconoclastas y críticos, de tendencias paródicas y humorísticas, el cual, a partir de procesos analógicos de cuestionamiento paródico, busca describir lo que nos aventuramos a llamar una historia crítica del Perú.

Continuemos con el análisis de un par de escenas significativas que ilustren el funcionamiento de estas secuencias analógicas, esta vez incursionando un poco en el plano semántico. Recordemos, para ello, lo dicho unas líneas arriba, a saber, que la representación paródica prioriza el cuestionamiento del proceso histórico apelando a su tendencia totalizadora, sin anclarse en la crítica a una tipología de sujetos sociales o puntos de vistas particulares. La parodia, en ese sentido, debe alcanzar tanto al sujeto empoderado (el colono esclavista o el político elitista) como 
al sujeto oprimido (esclavos, peones, campesinos) para infundir su sentido a todo el mecanismo social: se trata de una representación carnavalizada de la realidad. En «Esclavos y cimarrones I», el narrador realiza una rápida descripción paródica de diversos elementos constitutivos de la sociedad colonial en el contexto de la instauración de un palenque rebelde en Huachipa. Tenemos, por ejemplo, una representación analógica que compara dos centros de poder, a saber, la conocida Ciudad de los Reyes y el palenque antes mencionado, así como a sus respectivos habitantes. De Lima, se afirma lo siguiente:

[...] en honor a la verdad desnuda, nunca fue de los reyes sino apenas de visorreyes de capa caída y de media mampara porque, a la luz de los hechos concretos, la susodicha ciudad de Lima jamás tuvo, bajo su firmamento nubloso, color panza de burro, monarca imperial de testa coronada (1991: 39).

Y más adelante, durante la etapa republicana, se dice que esta se encuentra coronada por una cruz en la cumbre del cerro San Cristóbal, «un cerro de aspecto de mojón de cura» (1991: 170). Más allá de la alusión escatológica, un poco de observación nos permite discernir que para construir su parodia, el discurso no tiene más que exponer la realidad descarnada de una ciudad que ha escrito su historia sobre la base de un lenguaje ampuloso y la hipérbole irreal de sus características, o como afirmó en alguna ocasión Sebastián Salazar Bondy en su célebre libro Lima la horrible, una representación que «se conforma de supuestas abundancias y serenidades, sin que figure ahí la imaginable tensión entre amos y siervos» (1974: 14). En el mismo tono, podemos decir que, acerca del sujeto del poder y su relación con el sujeto oprimido, son usuales líneas de este tipo:

Toda aquella cáfila de cimarrones fuidos alegremente del recto gobierno de la esclavitud, y que al asumir con malicia aleve aquel ominoso desacato no habían abrigado en el pecho la menor consideración ni el más mínimo respeto por las ínfulas, los blasones, la honra y el buen nombre de sus amos (1991: 39) 
Se trata, por supuesto, de una forma paródica de lenguaje, a partir de la cual, haciendo uso de un léxico propio del discurso hegemónico religioso para descalificar lo que se encuentra fuera del orden oficial, se pretende brindar sentidos múltiples en ocasiones subversivos. Por ejemplo, al poner en relación ideas contradictorias como la esclavitud con el recto gobierno, o la consideración hacia la opresión con el buen nombre de los amos, se generan relaciones a las que Bajtín denomina disparidades carnavalescas, las cuales funcionan como mecanismos que refrescan los sentidos del discurso (2003: pág. 180). De este modo, a partir del lenguaje arcaizante de la crónica, da cuenta de un discurso cuyos sentidos, al ser actualizados por el lector, manifiestan una falta de sentido común, tópico usual en la sátira menipea.

Otro pasaje semejante trascurre cuando se afirma del palenque negro que es un "montal de satanás llamado Huachipa», en el cual «se congregaba en palenque endemoniado toda la negrada levantisca y de mala entraña que se había fuido» (1991: 39). Observamos nuevamente el empleo de un lenguaje propio del discurso hegemónico, pero desde una perspectiva paródica favorable al sujeto oprimido. En efecto, esta relación negro-demonio para construir el campo semántico del sujeto marginal en la novela (algo de ello se visualiza en el título general del relato) no tiene necesariamente un sentido negativo ni de deslegitimación. Pretende generar otros sentidos ocultos y positivos desde el punto de vista del otro, los cuales están relacionados con la rebelión, el placer vital de la sexualidad y el vínculo cósmico con la tierra. A Antonio Lucumí, líder de la rebelión cimarrona, le hará decir solemnemente, ante su inminente captura y muerte, en un maravilloso discurso indirecto libre, que él, "Antuco Lucumí, era un cimarrón marrajo y curtido que no necesitaba el perdón y menos todavía clemencia» (1991: 126), lo que evidencia que el lenguaje descalificador trabaja a partir del doble sentido.

Podemos observar claramente que la estrategia del narrador se asienta en una analogía en la que el lenguaje paródico permite comparar, por un lado, el lenguaje hegemónico oficial, con sus términos 
descalificadores, con una realidad otra de naturaleza subversiva. Este cotejo entre discurso/realidad conduce a reconocer la falta de sentido común de la crónica como discurso mimético de la historia, dado que se evidencia una falta de correspondencia entre lo que se intenta representar, a saber, la historia canónica, y lo que evidencia el doble discurso de la parodia, es decir, una historia mal representada. Esto produce, en términos de Vilahomat, una especie de «disolución aporística discursiva» (2010a: párr. 22) que tiene como principal objetivo desautorizar la capacidad mimética o representativa del discurso oficial.

\section{Conclusiones}

En resumen, Crónica de músicos y diablos es una novela cuya estructura narrativa evidencia notables relaciones dialógicas con la crónica histórica. Esto vínculos se evidencian en las diversas referencias que el relato hace respecto al discurso historiográfico. Particularmente, la nomenclatura que titula el libro, el empleo de usos lingüísticos propios del siglo xvI, la relevancia de la historia peruana y de lo colectivo por encima de los personajes individuales, y los vínculos con la crónica de Guamán Poma son algunas de las claves que grafican la intencionalidad del narrador. Teniendo en cuenta el carácter cuestionador que sostiene el discurso novelesco en relación con la historia oficial, es posible describir el comportamiento del texto en consonancia con el género cronístico, a fin de evidenciar que, incluso a nivel estructural, el relato plantea un conjunto de oposiciones críticas que desautorizan la capacidad mimética de la crónica.

En el marco de la teoría de los géneros cómico-serios establecida por Mijaíl Bajtín, la crítica latinoamericana ha establecido que, en nuestra región, desde los setenta se ha manifestado una tendencia literaria que sigue las pautas de la novela satírico-menipea. Consideramos que las características de esta tendencia novelesca son aplicables a Crónica de músicos y diablos, debido a su inclinación por la revisión histórica en una sociedad que se entiende en crisis, el tono paródico del discurso y el empleo de una fantasía liberada que permite, para el caso particular 
de la novela en cuestión, articular un discurso en el que la confrontación entre ficción y no ficción genera sentidos nuevos que permiten reescribir la historia hegemónica desde un punto de vista subversivo.

El análisis ha evidenciado que, desde el plano de la estructura, las formas narrativas de la novela tienen por fin poner en cuestionamiento la capacidad mimética de la crónica. El empleo de un narrador extradiegético/heterodiegético supone el abandono del estatuto de verdad que, para la crónica, se sostiene en la experiencia personal del cronista historiador. Ello le otorga al texto una visión totalizadora desde la cual se recorren grandes distancias de espacio y tiempo para brindar un panorama de los mecanismos de la historia peruana, los cuales evidencian una sociedad conflictiva en el que la opresión y el abuso se han normalizado con el transcurrir de los siglos. Por otro lado, la novela plantea lo que hemos denominado analogías paródicas, las cuales funcionan a partir de un paralelo entre las tendencias cómico-serias del relato. La apelación a las formas serias de la crónica implica el uso de un lenguaje descalificador de los sujetos marginales peruanos, sustentado ello en el orden divino y regio que organiza el sistema colonial. Este sistema es subvertido por medio de recursos carnavalescos como la parodia y la ironía, herramientas cuyo fin es desautorizar el discurso histórico como referente de la historia nacional. 
https://doi.org/10.46744/bapl.201901.006

\section{BIBLIOGRAFÍA}

ALBURQUERQUE GARCÍA, L. (2008). Apuntes sobre crónicas de Indias y relatos de viajes. En Letras. Revista de la Facultad de Filosofía y Letras de la Pontificia Universidad Católica Argentina Santa María de los Buenos Aires, 56-58, 11-23.

AUERBACH, E. (1996). Mimesis. La representación de la realidad en la literatura occidental. México: Fondo de Cultura Económica.

CARAZAS, M. (2011). Estudios Afroperuanos. Ensayos sobre identidad y literatura afroperuanas. Lima: Centro de Desarrollo Étnico.

CARRILlO, D. (2010). Novelar es una travesía. Crónica de músicos y diablos o la gesta del migrante. Tesis para optar por el título profesional de Licenciado en Literatura en la Universidad Nacional Mayor de San Marcos. Lima.

CIEZA DE LEÓN, P. (1988). La Crónica del Perú. Lima: Peisa.

BAJTÍN, M. (1998). La cultura popular en la Edad Media y el Renacimiento. El contexto de François Rabelais. Madrid: Alianza Editorial.

. (2003). Problemas de la poética de Dostoievski. 2. ${ }^{a}$ ed. México: Fondo de Cultura Económica.

BARTHES, R. (1972). Análisis estructural del relato. Buenos Aires: Tiempo Contemporáneo.

FORGUES, R. (2009). Gregorio Martínez, danzante de tijera. Lima: Editorial San Marcos.

FRYE, N. (2000). Anatomy of Criticism. $15^{\text {th }}$ Printing. Princeton: Princeton University Press. 
https://doi.org/10.46744/bapl.201901.006

GARCILASO DE LA VEGA, I. (1991). Comentarios reales de los Incas. México: Fondo de Cultura Económica.

GENETTE, G. (1989). Figuras III. Barcelona: Editorial Lumen.

HUESPE, A. (2012). Gregorio Martínez, cronista de otra historia. En Literatura y Lingüística, 26, 135-142.

MÁRQUEZ, I. (1994). Crónica de músicos y diablos de Gregorio Martínez: Desautorización del canon y metáfora de la escritura. En Chasqui. Revista de literatura latinoamericana, 1, 53-59.

MARTíneZ, G. (1991). Crónica de músicos y diablos. Lima: Peisa.

REVERTE BERNAL, C. (2018). Escribir en el aire frente a la cultura letrada (volviendo a Crónica de músicos y diablos, de Gregorio Martínez). En América sin nombre, 23, 231-241.

SALAS ANDRADE, N. (2009). La crónica periodística peruana. Lima: Editorial San Marcos - Universidad de Piura.

SALAZAR BONDY, S. (1974). Lima la horrible. Lima: Peisa.

VALENZUELA, J. (2006). La experiencia literaria del Grupo Narración: una aproximación a las crónicas. En El Grupo Narración en la narrativa peruana contemporánea. Materiales básicos para un estudio crítico. Néstor Tenorio (comp). Lima: Arteidea Editores.

VILAHOMAT, J. (2010a). Sátira híbrida y sujeto menipeo: la literatura cubana y latinoamericana actual. En Espéculo. Revista de estudios literarios, 44. Consultado el 5 de junio de 2019 en http://www.ucm.es/info/especulo/numero44/satirahi.html

. (2010b). Sátira menipea en trayecto: la literatura latinoamericana actual vuelve a los orígenes. Ptérodáctilo. 
https://doi.org/10.46744/bapl.201901.006

Revista de arte, literatura, lingüística y cultura, 9. Consultado el 4 de junio de 2019 en https://repositories.lib.utexas.edu/ bitstream/handle/2152/22880/Pterodactilo9_Critica Vilahomat.pdf? sequence $=9$ \&isAllowed $=\mathrm{y}$ 